\title{
PENELUSURAN BANJIR MENGGUNAKAN METODE LEVEL POOL ROUTING PADA WADUK KOTA LHOKSEUMAWE
}

\author{
Amalia $^{\text {1) }}$, Wesli ${ }^{2)}$ \\ ${ }^{1)}$ Alumni Teknik Sipil, ${ }^{2)}$ Dosen Jurusan Teknik Sipil, Universitas Malikussaleh \\ email: ${ }^{I)}$ dekamok@yahoo.com, ${ }^{2)}$ ir_wesli@yahoo.co.id
}

\begin{abstract}
Abstrak
Kota Lhokseumawe merupakan suatu dataran rendah di pesisir utara Provinsi Aceh yang dipengaruhi kondisi pasang-surut air laut sehingga harus dijaga kekeringannya dengan membangun tanggul dan sistem drainase. Salah satu sistem yang dibangun untuk menanggulangi kondisi ini adalah dengan membangun tempat penampungan air sementara yang disebut waduk atau reservoir. Untuk mengetahui efektivitas reservoir sebagai bangunan pengendali banjir dilakukan dengan analisis penelusuran banjir menggunakan Metode Level Pool Routing. Metode ini diperlukan untuk mengetahui jumlah debit maksimum yang mampu ditampung reservoir. Dengan jumlah debit yang tertampung tersebut dapat dilakukan komparasi terhadap debit hasil analisis hidrologi menggunakan Metode Rasional. Metode ini diperlukan untuk memperoleh debit limpasan yang mengalir dari kota Lhokseumawe ke reservoir. Berdasarkan hasil analisis menggunakan Metode Level Pool Routing, didapatkan bahwa volume tampungan maksimum sebagai kapasitas reservoir adalah sebesar 1023440,987 $\mathrm{m}^{3}$ dengan jumlah debit maksimum yang ditampung oleh reservoir adalah sebesar $856,49 \mathrm{~m}^{3} / \mathrm{det}$. Sedangkan debit limpasan dengan periode ulang 5 tahun yang dihitung menggunakan Metode Rasional adalah sebesar 42,17 $\mathrm{m}^{3} / \mathrm{det}$. Dari hasil komparasi kedua metode tersebut dapat disimpulkan bahwa saat kondisi hujan reservoir hanya mampu menampung jumlah debit yang mengalir dari Kota Lhokseumawe selama 6,74 jam saja dengan mengasumsikan semua aliran mengalir dengan lancar.
\end{abstract}

Kata Kunci: Banjir, Level Pool Routing, Reservoair

\section{Pendahuluan}

Banjir merupakan suatu peristiwa tergenangnya suatu wilayah dengan air, baik itu air hujan, air sungai, maupun air pasang. Hal ini dapat terjadi akibat ketidakmampuan suatu saluran untuk menampung jumlah aliran air yang relatif tinggi. Salah satu cara teknis untuk mengendalikannya adalah dengan dibangunnya sebuah wadah penampungan air sementara yang biasa disebut dengan waduk atau reservoir. Adapun fungsi dari reservoir adalah untuk menampung semua air limpasan hujan, air pasang, air limbah rumah tangga, perkantoran, pusat perbelanjaan dan bangunan lainnya. Semua limbah pembuangan yang terkumpul di reservoir nantinya akan dialirkan ke laut melalui pintu air otomatis yang hanya bisa terbuka pada saat kondisi air laut surut.

Hubungan reservoir dan sistem drainase di Kota Lhokseumawe adalah pada saat datangnya musim hujan jumlah debit limpasan air hujan yang mengalir ke reservoir meningkat, dan kondisi air laut pun pasang. Oleh karena itu perlu dilakukannya analisa terhadap debit limpasan yang akan terjadi jika pada saat musim penghujan pintu air di reservoir tertutup akibat pasang tinggi. Analisa ini 
diperlukan untuk mengetahui apakah besar tampungan yang dimiliki reservoir mampu untuk menampung seluruh jumlah air limpasan yang mengalir di saluransaluran drainase Kota Lhokseumawe pada saat musim penghujan. Adapun analisa yang digunakan untuk kasus ini adalah analisa penelusuran aliran (flow routing) atau bisa disebut juga dengan penelusuran banjir (flood routing) jika aliran tersebut merupakan banjir dengan menggunakan metode Level Pool Routing, analisa untuk membangkitkan data sintetik dengan menggunakan metode Tabel Bilangan Acak dan Proses Markov, serta analisa hidrologi dengan menggunakan metode Rasional. Tujuan penelitian ini untuk mengetahui besarnya debit yang masuk maupun keluar pada waduk sehingga diketahui keefektifannya sebagai bangunan pengendali banjir. Manfaat penelitian ini dapat menunjukkan keefektifan waduk selama jangka waduk tertentu untuk mampu menampung debit aliran pada saat musim penghujan.

\section{Tinjauan Kepustakaan}

\subsection{Penelusuran Banjir}

Menurut Kamiana (2011), yang dimaksud dengan penelusuran aliran adalah suatu cara atau teknik matematika yang digunakan untuk melacak aliran melalui sistem hidrologi. Dalam literatur lainnya, dijelaskan bahwa penelusuran aliran adalah cara atau prosedur yang digunakan untuk memperkirakan perubahan unsurunsur aliran sebagai fungsi waktu di satu atau di beberapa titik tinjauan di sepanjang ruas sungai. Ditinjau dari titik tinjauan dan persamaan pengaturnya, teknik penelusuran aliran atau debit atau debit rencana dikelompokkan menjadi 2 yaitu penelusuran hidrologis dan penelusuran hidraulik. Menurut Chow (1988), Flow Routing adalah suatu cara untuk menentukan besarnya debit aliran dan waktu terjadinya debit tersebut pada suatu titik di sepanjang aliran sungai dengan menggunakan hidrograf aliran di daerah hulu titik tersebut. Jika aliran tersebut merupakan banjir (flood), maka disebut penelusuran banjir (flood routing).

\subsubsection{Penelusuran elevasi genangan (level pool routing)}

Menurut Kamiana (2011), dalam penelusuran kolam datar LPR (Level Pool Routing), persamaan kontinuitas yang digunakan dapat ditulis sebagai berikut:

$$
\left[\begin{array}{ccc}
2 S_{j+1} & \mid & Q_{j+1} \\
\Delta t & &
\end{array}\right]=\left[\begin{array}{lll}
I_{j} & \mid & I_{j+1}
\end{array}\right] \text { । }\left[\begin{array}{cc}
2 S_{j} & Q_{j} \\
\Delta t &
\end{array}\right]
$$

Dari persamaan 1 di atas dapat dilihat:

a. Suku di sebelah kiri sama dengan nilainya tidak diketahui

b. Suku di sebelah kanan sama dengan nilainya diketahui

Penyelesaian suku yang belum diketahui nilainya itu memerlukan 3 fungsi yang menggambarkan hubungan antara:

a. Ketinggian air dan tampungan ( $\mathrm{H}$ dan $\mathrm{S})$

Hubungan antara ketinggian dan tampungan dapat ditentukan dengan mengalikan antara kedalaman air dengan luas tampungan. Seperti persamaan berikut:

$$
S=A_{:} x H
$$


b. Ketinggian air dan Outflow $(\mathrm{H}-\mathrm{Q})$

Hubungan antara ketinggian air dan outflow bergantung dari type bangunan outflow, seperti bendung atau spillway, terowongan, waduk, gorong-gorong, dan sebagainya. Adapun dalam kasus ini bangunan yang digunakan adalah berupa pintu air, maka persamaannya adalah sebagai berikut:

$$
Q=C d x A_{2} x(2 g H)^{\frac{1}{2}}
$$

c. Outflow dan tampungan

Untuk fungsi yang ketiga ini persamaan yang digunakan adalah sebagai berikut:

$$
\frac{2 S}{\Delta \tau}+Q
$$

Selanjutnya setelah ketiga fungsi di atas telah didapatkan hasilnya, maka dapat dilanjutkan untuk menentukan besarnya debit limpasan maksimum dan debit total reservoir dengan menggunakan persamaan-persamaan di bawah ini:

$$
\begin{aligned}
& {\left[\frac{2 S_{j+1}}{\Delta t}-Q_{j+1}\right]=\left[\frac{2 S_{j-1}}{\Delta t}+Q_{j+1}\right]-2 Q_{j+1}} \\
& \mathrm{Q}_{\text {maksimum }}=\mathrm{Q}_{\text {inflow }} \text { Maksimum - } \mathrm{Q}_{\text {outflow }} \text { Maksimum. } \\
& \mathrm{Q}_{\text {total }}=\text { Total debit in-flow }- \text { Total debit out-flow }
\end{aligned}
$$

Keterangan:

$$
\begin{array}{ll}
\mathrm{S} & =\text { Tampungan }(\text { storage })\left(\mathrm{m}^{3}\right) \\
\mathrm{Q} & =\text { Debit } \text { out-flow }\left(\mathrm{m}^{3} / \mathrm{det}\right) \\
\mathrm{t} & =\text { Selang waktu }(\mathrm{det}) \\
\mathrm{I} & =\text { Debit in-flow }\left(\mathrm{m}^{3} / \mathrm{det}\right) \\
\mathrm{j} & =\text { Indeks } \\
\mathrm{A}_{1} & =\text { Luas reservoir } \\
\mathrm{A}_{2} & =\text { Luas penampang bukaan }\left(\mathrm{m}^{2}\right) \\
\mathrm{H} & =\text { Elevasi muka air reservoir }(\mathrm{m}) \\
\mathrm{g} & =\text { Gaya gravitasi bumi }\left(9,8 \mathrm{~m} / \mathrm{dt}^{2}\right) \\
\mathrm{Cd} & =\text { Koefisien debit } 0,62(\text { Triatmodjo, 1993) }
\end{array}
$$

\subsubsection{Kurva massa (mass curve)}

Menurut Suyono (1976), kurva massa adalah kurva hubungan antara curah hujan dengan satuan waktu. Curah hujan daerah pada suatu waktu tertentu dalam daerah yang bersangkutan, dapat ditentukan dari kurva massa ini. Jika di daerah yang bersangkutan terdapat beberapa buah pos pengamatan curah hujan, maka kesalahan-kesalahan pengamatan dapat diketahui dari bentuk kurva massa pos-pos tersebut yang digambar bersama-sama pada sebuah sistem koordinat. Dari kurva massa dapat ditentukan juga debit aliran limpasan yang terjadi pada reservoir, melalui hubungan debit in-flow dan out-flow dengan satuan waktu. 


\subsection{Analisis Hidrologi}

\subsubsection{Debit aliran}

Menurut Triatmodjo (1993), debit aliran adalah jumlah zat cair yang mengalir melalui tampang lintang aliran tiap satuan waktu dan diberi notasi Q. Debit aliran biasanya diukur dalam volume zat cair tiap satuan waktu. Untuk menentukan besarnya debit aliran digunakan persamaan berikut:

$$
Q=A \times V
$$

Untuk menghitung besarnya kecepatan aliran yang terjadi dapat digunakan persamaan manning sebagai berikut:

$$
\begin{aligned}
V & =\frac{1}{n} \times R^{\frac{2}{3}} \times l^{\frac{1}{2}} \\
R & =\frac{A}{P}
\end{aligned}
$$

Keterangan:

$$
\begin{array}{ll}
\mathrm{Q} & =\text { Debit aliran }\left(\mathrm{m}^{3} / \mathrm{det}\right) \\
\mathrm{V} & =\text { Kecepatan aliran }(\mathrm{m} / \mathrm{det}) \\
\mathrm{A} & =\text { Luas penampang basah }\left(\mathrm{m}^{2}\right) \\
\mathrm{R} & =\text { Jari-jari hidraulis }(\mathrm{m}) \\
\mathrm{I} & =\text { Kemiringan saluran }(\mathrm{m}) \\
\mathrm{P} & =\text { Keliling penampang basah }(\mathrm{m}) \\
\mathrm{n} & =\text { Koefisien manning }
\end{array}
$$

\subsubsection{Analisis curah hujan rencana}

Menurut Chow (1992), perhitungan curah hujan rencana dilakukan dengan menggunakan persamaan berikut:

$$
X_{T}=\bar{X}+K \cdot S_{D}
$$

Keterangan:

$\mathrm{X}_{\mathrm{T}}=$ Tinggi curah hujan rencana dengan periode ulang $\mathrm{T}$ tahun $(\mathrm{mm})$

$\overline{\mathrm{X}}=$ Rata-rata tinggi curah hujan (mm)

$\mathrm{S}_{\mathrm{D}}=$ Simpangan baku dari data tinggi curah hujan

$\mathrm{K}=$ Faktor frekuensi sesuai dengan distribusi frekuensi

\subsubsection{Koefisien aliran}

Menurut Wesli (2008), koefisien aliran (runoff coefficient) adalah perbandingan antara jumlah air hujan yang mengalir atau melimpas di atas permukaan tanah (surface runoff) dengan jumlah air hujan yang jatuh dari atmosfer. Koefisien aliran dapat dihitung dengan menggunakan persamaan sebagai berikut:

$$
C=\frac{\sum_{i=1}^{n} C_{i} \cdot A_{i}}{\sum_{i=1}^{n} A_{i}}
$$

Keterangan:

$$
\begin{aligned}
& \mathrm{A}_{\mathrm{i}}=\text { Luas lahan dengan penutup tanah } \mathrm{i} \\
& \mathrm{C}_{\mathrm{i}}=\text { Koefisien aliran permukaan (runoff) jenis penutup } \mathrm{i} \\
& \mathrm{n}=\text { Jumlah jenis penutup lahan }
\end{aligned}
$$




\subsubsection{Waktu konsentrasi}

Menurut Wesli (2008), waktu konsentrasi adalah waktu yang diperlukan untuk mengalirkan air dari titik yang paling jauh pada daerah aliran ke titik kontrol yang ditentukan di bagian hilir suatu saluran. Waktu konsentrasi dapat ditentukan berdasarkan panjang saluran yang dilalui aliran dan kemiringan saluran, seperti yang ditunjukkan pada persamaan Kirpich berikut ini:

$$
T_{c}=\left(\frac{0,87 \times L^{2}}{1000 \times S}\right)^{0,385}
$$

Keterangan:

$\mathrm{T}_{\mathrm{c}}=$ Waktu konsentrasi (jam)

$\mathrm{L}=$ Panjang lintasan aliran dari titik terjauh sampai titik tinjauan $(\mathrm{Km})$

$\mathrm{S}=$ Kemiringan rata-rata daerah aliran air

\subsubsection{Intensitas Hujan}

Menurut Loebis (1992), intensitas hujan dapat ditentukan secara empiris berdasarkan data hujan jangka pendek, diantaranya dengan menggunakan metode Talbot, Ishiguro, dan Sherman. Namun apabila data hujan jangka pendek tidak tersedia, penentuan intensitas hujan dapat didasarkan pada data hujan harian yaitu dengan menggunakan metode Mononobe sebagaimana ditunjukkan dalam bentuk persamaan sebagai berikut:

$$
I=\frac{X_{z 4}}{24}\left(\frac{24}{T_{c}}\right)^{\frac{2}{2}}
$$

Keterangan:

$$
\begin{aligned}
& \mathrm{I}=\text { Intensitas curah hujan (mm/jam) } \\
& \mathrm{X}_{24}=\text { Curah hujan maksimum harian selama } 24 \text { jam (mm) } \\
& \mathrm{T}_{\mathrm{c}}=\text { Waktu konsentrasi (jam) }
\end{aligned}
$$

\subsubsection{Metode Rasional}

Menurut Suripin (2004), penggunaan Metode Rasional pada daerah pengaliran dengan beberapa sub daerah pengaliran dapat dilakukan dengan pendekatan nilai koefisien aliran gabungan atau rata-rata dan intensitas hujan dihitung berdasarkan waktu konsentrasi yang terpanjang. Besarnya debit limpasan dapat ditentukan dengan Metode Rasional berdasarkan pada hubungan rasional antara air hujan dengan limpasannnya yang diformulasikan dalam bentuk persamaan sebagai berikut:

$$
Q=0,278 \cdot C \cdot I \cdot A
$$

Keterangan:

$$
\begin{aligned}
& \mathrm{Q}=\text { Debit puncak limpasan permukaan }\left(\mathrm{m}^{3} / \mathrm{det}\right) \\
& \mathrm{C}=\text { Koefisien pengaliran }(\operatorname{tanpa} \text { dimensi) } \\
& \mathrm{A}=\text { Luas daerah pengaliran }\left(\mathrm{Km}^{2}\right) \\
& \mathrm{I}=\text { Intensitas curah hujan }(\mathrm{mm} / \mathrm{jam})
\end{aligned}
$$

\section{Metode Penelitian}

Data yang diperoleh terdiri dari pengamatan langsung di lapangan. Data-data penunjang lainnya diperoleh dari studi literatur. Data primer yang digunakan adalah data hubungan kedalaman aliran dengan waktu yang diperoleh dari penelitian di lapangan, serta data topografi dan data kontur. 


\subsection{Pengolahan data dengan Metode level pool routing (LPR)}

Pengolahan data yang pertama adalah menghitung debit Inflow yang masuk ke reservoir dengan menggunakan data hubungan waktu dengan kedalaman aliran sehingga diperoleh data baru yaitu data hubungan waktu dengan debit Inflow, selanjutnya adalah pengolahan data topografi dan kontur sehingga didapatkan data hubungan storage dengan debit outflow. Kemudian, dengan menggunakan data hubungan storage dengan debit outflowdan disertai data hubungan waktu dengan debit in-flow yang ada, maka dapat dihitung debit limpasan maksimum dengan menggunakan konsep perhitungan Flow Routing yaitu Metode Level Pool Routing (LPR) (Chow, 1988). Konsep ini menghasilkan sebuah rumus debit limpasan pada reservoir dimusim penghujan.

\subsection{Pengolahan data dengan Metode rasional}

Analisis hidrologi dengan menggunakan Metode Rasional yang di dukung dengan perhitungan analisis frekuensi, distribusi probabilitas, dan pengujian distribusi probabilitas sehingga menghasilkan jumlah debit rencana yang mengalir ke reservoir.

\section{Hasil dan Pembahasan}

\subsection{Penelusuran banjir}

\subsubsection{Debit aliran}

Berdasarkan dengan data hasil pengukuran hubungan kedalaman aliran dengan waktu, debit aliran yang masuk ke dalam reservoir atau bisa dikatakan dengan debit inflow diperlihatkan pada Tabel 1.

Tabel 1 Hubungan debit inflow dengan waktu

\begin{tabular}{|c|c|c|c|c|}
\hline No. & Waktu (menit) & Debit Inflow & Waktu (menit) & Debit Inflow \\
\hline 1 & 0 & 0,00 & 690 & 24,93 \\
\hline 2 & 30 & 1,40 & 720 & 25,48 \\
\hline 3 & 60 & 1,98 & 750 & 23,84 \\
\hline 4 & 90 & 2,63 & 780 & 22,25 \\
\hline 5 & 120 & 3,35 & 810 & 20,66 \\
\hline 6 & 150 & 4,23 & 840 & 19,02 \\
\hline 7 & 180 & 4,98 & 870 & 17,65 \\
\hline 8 & 210 & 5,90 & 900 & 16,13 \\
\hline 9 & 240 & 6,82 & 930 & 14,67 \\
\hline 10 & 270 & 7,86 & 960 & 13,24 \\
\hline 11 & 300 & 8,87 & 990 & 11,92 \\
\hline 12 & 330 & 9,96 & 1020 & 10,63 \\
\hline 13 & 360 & 11,05 & 1050 & 9,39 \\
\hline 14 & 390 & 12,27 & 1080 & 8,26 \\
\hline 15 & 420 & 13,48 & 1110 & 7,12 \\
\hline 16 & 450 & 14,76 & 1140 & 5,99 \\
\hline 17 & 480 & 15,93 & 1170 & 5,02 \\
\hline 18 & 510 & 17,27 & 1200 & 4,08 \\
\hline 19 & 540 & 18,62 & 1230 & 3,22 \\
\hline 20 & 570 & 20,08 & 1260 & 2,17 \\
\hline 21 & 600 & 21,36 & 1290 & 1,74 \\
\hline 22 & 630 & 22,80 & 1320 & 1,12 \\
\hline 23 & 660 & 24,32 & 1350 & 0,00 \\
\hline
\end{tabular}

\subsubsection{Karakteristik hubungan reservoir - outflow}

Berdasarkan hasil perhitungan, karakteristik hubungan antara reservoir outflow dapat diperlihatkan pada Tabel 2. 
Tabel 2 Karakteristik hubungan reservoir - outflow

\begin{tabular}{|c|c|c|c|c|}
\hline No. & $\begin{array}{c}\text { Elev. } \\
\text { Gendangan (H) } \\
\mathrm{m}\end{array}$ & $\begin{array}{c}\text { Debit Outflow (Q) } \\
\mathrm{m}^{3} / \text { det }\end{array}$ & $\begin{array}{c}\text { Storage (S) } \\
\mathrm{m}^{3}\end{array}$ & $\begin{array}{c}(2 \mathrm{~S} / \Delta \mathrm{t}+\mathrm{Q}) \\
\mathrm{m}^{3} / \mathrm{det}\end{array}$ \\
\hline 1 & 0,00 & 0,000 & 0,000 & 0 \\
\hline 2 & 0,25 & 0,296 & 60507,875 & 68 \\
3 & 0,50 & 0,838 & 183834,988 & 205 \\
\hline 4 & 0,75 & 1,540 & 311858,190 & 348 \\
\hline 5 & 1,00 & 2,372 & 445759,718 & 498 \\
\hline 6 & 1,25 & 3,314 & 585292,830 & 654 \\
\hline 7 & 1,50 & 4,357 & 728270,630 & 814 \\
\hline 8 & 1,75 & 5,490 & 874391,080 & 977 \\
\hline 9 & 2,00 & 6,708 & 1023440,987 & 1144 \\
\hline 10 & 2,25 & 8,004 & 0,000 & 0 \\
\hline
\end{tabular}

Berdasarkan dari data pengukuran yang didapat di lapangan dan didukung dengan analisis lanjut sebagaimana yang hasilnya telah diperlihatkan pada Tabel 2 maka hubungan karakteristik antara reservoir - outflow dapat digambarkan dalam bentuk grafik seperti yang diperlihat pada gambar 1 .

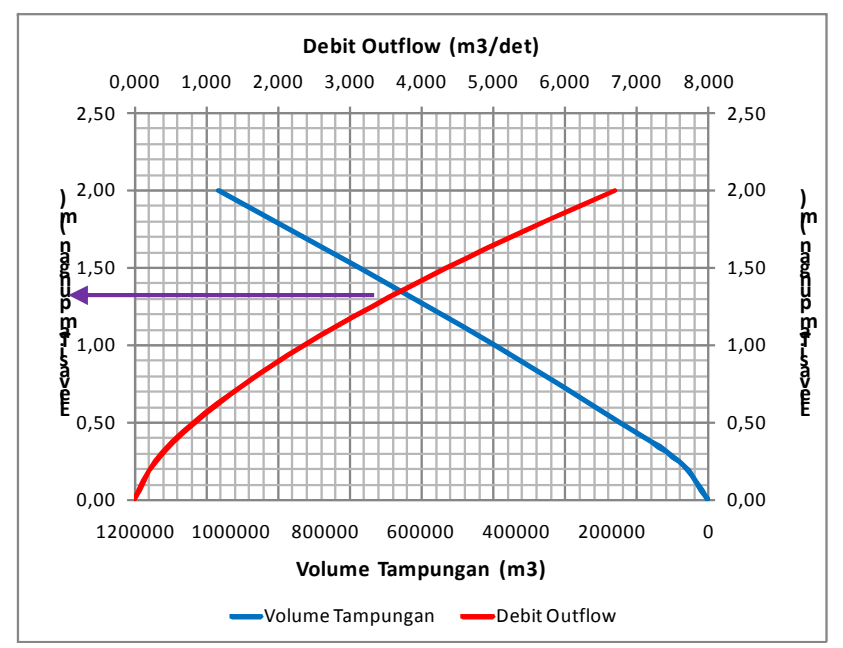

\section{Gambar 1 Grafik hubungan elevasi dengan tampungan dan debit outflow}

\subsubsection{Flood routing debit outflow}

Berdasarkan hasil perhitungan karakteristik hubungan reservoir - outflow pada Tabel 2,maka hasil perhitungan debit outflow dengan menggunakan Metode Level Pool Routing (LPR) diperlihatkan pada Tabel 3.

Tabel 3 Flood routing debit outflow

\begin{tabular}{|c|c|c|c|c|c|c|}
\hline $\begin{array}{l}\text { Indeks } \\
\mathbf{j}\end{array}$ & $\begin{array}{l}\text { Waktu } \\
\text { (menit) }\end{array}$ & $\begin{array}{l}\text { Inflow } \\
\left(\mathrm{m}^{3} / \text { det }\right)\end{array}$ & $\begin{array}{c}\left(I_{i}+I_{i+1}\right) \\
\left(\mathrm{m}^{3} / \mathrm{det}\right)\end{array}$ & $\begin{array}{c}\left(2 S_{i} / \Delta t-Q_{i}\right) \\
\left(m^{3} / \text { det }\right)\end{array}$ & $\begin{array}{c}\left(2 S_{i+1} / \Delta t+Q_{i+1}\right) \\
\left(\mathbf{m}^{3} / \text { det }\right)\end{array}$ & $\begin{array}{l}\text { Outflow } \\
\left(\mathrm{m}^{3} / \text { det }\right)\end{array}$ \\
\hline (1) & (2) & (3) & (4) & (5) & (6) & (7) \\
\hline 1 & 0 & 0 & & 0,00 & & 0,00 \\
\hline 2 & 30 & 1,40 & 1,40 & 1,39 & 1,40 & 0,006 \\
\hline 3 & 60 & 1,98 & 3,38 & 4,73 & 4,77 & 0,021 \\
\hline 4 & 90 & 2,63 & 4,61 & 9,25 & 9,34 & 0,041 \\
\hline 5 & 120 & 3,35 & 5,98 & 15,10 & 15,23 & 0,067 \\
\hline 6 & 150 & 4,23 & 7,58 & 22,48 & 22,68 & 0,100 \\
\hline 7 & 180 & 4,98 & 9,21 & 31,41 & 31,69 & 0,139 \\
\hline 8 & 210 & 5,90 & 10,88 & 41,92 & 42,29 & 0,186 \\
\hline 9 & 240 & 6,82 & 12,72 & 54,16 & 54,64 & 0,240 \\
\hline 10 & 270 & 7,86 & 14,68 & 68,24 & 68,84 & 0,302 \\
\hline
\end{tabular}




\begin{tabular}{|c|c|c|c|c|c|c|}
\hline$\pi 1$ & 300 & 8,87 & 16,73 & 84,22 & 84,97 & 0,373 \\
\hline 12 & 330 & 9.96 & 18,83 & 102,15 & 103,05 & 0.452 \\
\hline 13 & 360 & 11,05 & 21,01 & 122,08 & 123,16 & 0,541 \\
\hline 14 & 390 & 12,27 & 23,32 & 144,12 & 145,40 & 0,638 \\
\hline 15 & 420 & 13,48 & 25,75 & 168,47 & 169,87 & 0,700 \\
\hline 16 & 450 & 14,76 & 28,24 & 195,10 & 196,71 & 0,805 \\
\hline 17 & 480 & 15,93 & 30,69 & 223,95 & 225,79 & 0,920 \\
\hline 18 & 510 & 17,27 & 33,20 & 255,06 & 257,15 & 1,044 \\
\hline 19 & 540 & 18,62 & 35,89 & 288,60 & 290,95 & 1,177 \\
\hline 20 & 570 & 20,08 & 38,70 & 324,42 & 327,30 & 1,438 \\
\hline 21 & 600 & 21,36 & 41,44 & 362,61 & 365,86 & 1,628 \\
\hline 22 & 630 & 22,80 & 44,16 & 403,11 & 406,77 & 1,829 \\
\hline 23 & 660 & 24,32 & 47,12 & 446,14 & 450,23 & 2,042 \\
\hline 24 & 690 & 24,93 & 49,25 & 490,68 & 495,39 & 2,359 \\
\hline 25 & 720 & 25,48 & 50,41 & 535,86 & 541,09 & 2,613 \\
\hline 26 & 750 & 23,84 & 49,32 & 579,46 & 585,18 & 2,858 \\
\hline 27 & 780 & 22,25 & 46,09 & 619,39 & 625,55 & 3,082 \\
\hline 28 & 810 & 20,66 & 42,91 & 655,73 & 662,30 & 3,286 \\
\hline 29 & 840 & 19,02 & 39,68 & 688,27 & 695,41 & 3,567 \\
\hline 30 & 870 & 17,65 & 36,67 & 717,45 & 724,94 & 3,745 \\
\hline 31 & 900 & 16,13 & 33,78 & 743,43 & 751,23 & 3,904 \\
\hline 32 & 930 & 14,67 & 30,80 & 766,14 & 774,23 & 4,043 \\
\hline 33 & 960 & 13,24 & 27,91 & 785,72 & 794,05 & 4,163 \\
\hline 34 & 990 & 11,92 & 25,16 & 802,20 & 810,88 & 4,339 \\
\hline 35 & 1020 & 10,63 & 22,55 & 815,89 & 824,75 & 4,430 \\
\hline 36 & 1050 & 9,39 & 20,02 & 826,91 & 835,91 & 4,503 \\
\hline 37 & 1080 & 8,26 & 17,65 & 835,44 & 844,56 & 4,559 \\
\hline 38 & 1110 & 7,12 & 15,38 & 841,62 & 850,82 & 4,600 \\
\hline 39 & 1140 & 5.99 & 13.11 & 845.48 & 854.73 & 4.625 \\
\hline 40 & 1170 & 5,02 & 11,01 & 847,22 & 856,49 & 4,637 \\
\hline 41 & 1200 & 4,08 & 9,10 & 847,05 & 856,32 & 4,636 \\
\hline 42 & 1230 & 3,22 & 7,30 & 845,10 & 854,35 & 4,623 \\
\hline 43 & 1260 & 2,47 & 5,69 & 841,59 & 850,79 & 4,600 \\
\hline 44 & 1290 & 1,74 & 4,21 & 836,67 & 845,80 & 4,567 \\
\hline 45 & 1320 & 1,12 & 2,86 & 830,47 & 839,53 & 4,526 \\
\hline 46 & 1350 & 0,00 & 1,12 & 822,65 & 831,59 & 4,474 \\
\hline 47 & 1380 & 0,00 & 0,00 & 813,81 & 822,65 & 4,416 \\
\hline 48 & 1410 & 0,00 & 0,00 & 805,10 & 813,81 & 4,359 \\
\hline 49 & 1440 & 0,00 & 0,00 & 796,49 & 805,10 & 4,302 \\
\hline 50 & 1470 & 0,00 & 0,00 & 788,00 & 796,49 & 4,246 \\
\hline 51 & 1500 & 0,00 & 0,00 & 779,62 & 788,00 & 4,190 \\
\hline 52 & 1530 & 0,00 & 0,00 & 771,35 & 779,62 & 4,136 \\
\hline 53 & 1560 & 0,00 & 0,00 & 763,30 & 771,35 & 4,026 \\
\hline
\end{tabular}

Berdasarkan hasil perhitungan flow routing pada Tabel 3 dapat dilihat bahwa besar debit tampungan maksimum adalah sebesar $856,49 \mathrm{~m}^{3} / \mathrm{det}$ (kol.6 J.40), dan besar debit outflow maksimum adalah sebesar 4,637 $\mathrm{m}^{3} / \mathrm{det}$ (kol.7 J.40), maka hidrograf outflow dan inflow dapat disajikan dalam bentuk grafik seperti yang diperlihatkan pada gambar 2 .

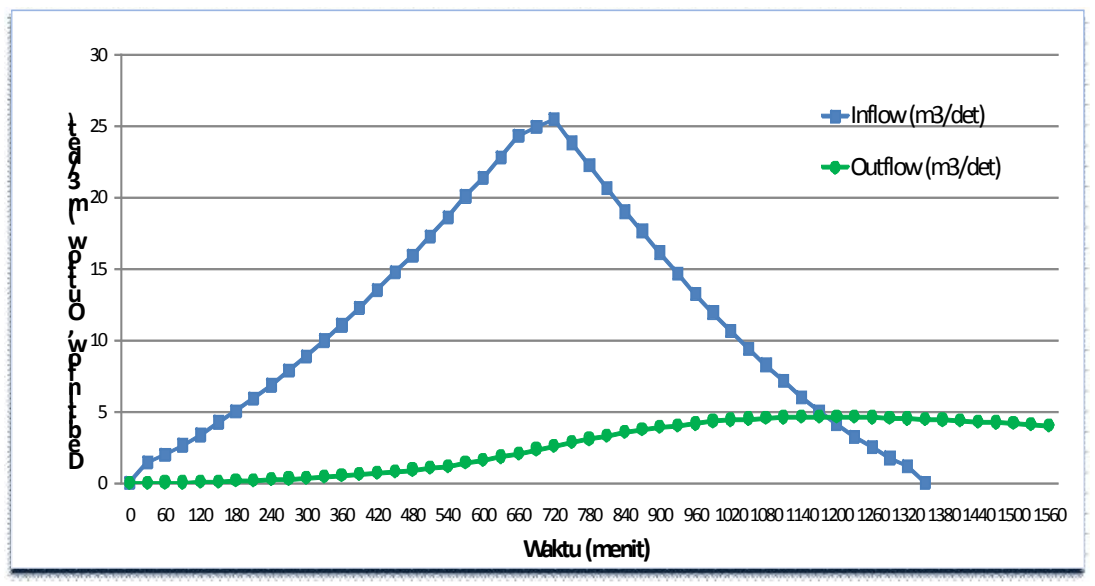

Gambar 2 Hidrograf Outflow dan Inflow

Penelusuran Banjir Menggunakan Metode Level Pool Routing Pada Waduk Kota

Lhokseumawe - Amalia, Wesli 


\subsection{Analisis hidrologi}

\subsubsection{Curah Hujan}

Data curah hujan yang digunakan adalah data curah hujan selama 25 tahun seperti diperlihatkan padaTabel 4 .

Tabel 4 Rekapitulasi data curah hujan tahunan

\begin{tabular}{|c|c|c|c|c|}
\hline No. & Tahun & $\begin{array}{c}\text { Curah Hujan } \\
(\mathrm{mm})\end{array}$ & Tahun & $\begin{array}{c}\text { Curah Hujan } \\
(\mathrm{mm})\end{array}$ \\
\hline 1 & 1988 & 305,2 & 2001 & 358,0 \\
\hline 2 & 1989 & 407.9 & 2002 & 134.4 \\
\hline 3 & 1990 & 478,7 & 2003 & 165,7 \\
\hline 4 & 1991 & 321,5 & 2004 & 225,1 \\
\hline 5 & 1992 & 216,7 & 2005 & 412,8 \\
\hline 6 & 1993 & 259,9 & 2006 & 231,2 \\
\hline 1 & 1994 & 388,1 & $200 /$ & 285,6 \\
\hline 8 & 1995 & 271,3 & 2008 & 402,1 \\
\hline 9 & 1996 & 411,5 & 2009 & 428,1 \\
\hline 10 & 1997 & 437,3 & 2010 & 294,5 \\
\hline 11 & 1998 & 440.2 & 2011 & 283.3 \\
\hline 12 & 1999 & 329,1 & 2012 & 306,0 \\
\hline 13 & 2000 & 696,7 & \multicolumn{2}{|l}{} \\
\hline
\end{tabular}

Berdasarkan metode Gumbel, data yang digunakan dalam analisis merupakan data curah hujan. Data curah hujan ini diperlukan menentukan tinggi curah hujan rata-rata $(\mathrm{X})$ dan standar devisiasi $\left(\mathrm{S}_{\mathrm{D}}\right)$ sebagai pendukung untuk melaksanakan tahapan perhitungan selanjutnya dalam analisis hidrologi. Berdasarkan hasil perhitungan, didapat nilai X sebesar 339,64 mm dan $\mathrm{S}_{\mathrm{D}}$ sebesar $117,33 \mathrm{~mm}$.

\subsubsection{Uji distribusi probabilitas}

Berdasarkan tahapan-tahapan perhitungan pengujian distribusi didapatkan nilai $\mathrm{P}$ maksimum sebesar 0,05 dan $\mathrm{P}$ kritis sebesar 0,27 . Berdasarkan syarat yang berlaku yaitu $\mathrm{P}$ maksimum lebih kecil dari $\mathrm{P}$ kritis, maka distribusi probabilitas Gumbel dapat diterima untuk menganalisis data hujan.

\subsubsection{Analisis curah hujan rencana}

Analisis curah hujan dapat dihitung sesuai dengan periode ulang yang dibutuhkan. Dalam penelitian ini, analisis curah hujan dihitung dengan periode ulang 2, 5, 10, 20, 25, 50 dan 100 tahun.

Tabel 5 Curah hujan rencana

\begin{tabular}{|c|c|c|c|c|c|c|c|c|}
\hline No. & $\begin{array}{c}\text { Periode Ulang, } \\
\mathrm{T} \text { (Tahun) }\end{array}$ & $\mathrm{Sn}$ & $\mathrm{Yn}$ & $\mathrm{Yt}$ & $\mathrm{k}$ & $\mathrm{X}_{\mathrm{i}}$ & $\mathrm{S}_{\mathrm{D}}$ & $\begin{array}{c}\mathrm{X}_{\mathrm{T}} \\
(\mathrm{mm})\end{array}$ \\
\hline 1 & 2 & 3 & 4 & 5 & 6 & 7 & 8 & 9 \\
\hline 1 & 2 & 1,0915 & 0,5309 & 0,3668 & $-0,150$ & 339,64 & 117,33 & 322,00 \\
\hline 2 & 5 & 1,0915 & 0,5309 & 1,5004 & 0,888 & 339,64 & 117,33 & 443,86 \\
\hline 3 & 10 & 1,0915 & 0,5309 & 2,2510 & 1,576 & 339,64 & 117,33 & 524,54 \\
\hline 4 & 20 & 1,0915 & 0,5309 & 2,9709 & 2,235 & 339,64 & 117,33 & 601,93 \\
\hline 5 & 25 & 1,0915 & 0,5309 & 3,1993 & 2,445 & 339,64 & 117,33 & 626,48 \\
\hline 6 & 50 & 1,0915 & 0,5309 & 3,9028 & 3,089 & 339,64 & 117,33 & 702,10 \\
\hline 7 & 100 & 1,0915 & 0,5309 & 4,6012 & 3,729 & 339,64 & 117,33 & 777,17 \\
\hline
\end{tabular}




\subsubsection{Koefisien aliran}

Berdasarkan data topografi yang berupa gambar peta Kota Lhokseumawe dengan skala 1:1 dimana terbagi atas blok 1, blok 2, dan blok 3, dapat ditentukan luas lahan dengan menggunakan bantuan Software AutoCad, didapat nilai koefisien dari blok 1 adalah sebesar 0,62, blok 2 sebesar 0,70, dan blok 3 sebesar 0,75 .

\subsubsection{Waktu konsentrasi}

Waktu konsentrasi di tentukan dengan mengetahui panjangnya jarak tempuh aliran dan kemiringan saluran. Jarak tempuh aliran diperoleh dengan mengukur panjang saluran dari titik terjauh sampai ke titik pengukuran dengan menggunakan bantuan peta topografi dan Software AutoCad. Sedangkan untuk data kemiringan saluran telah diperoleh dari PT. Jaya Konstruksi.Waktu konsentrasi $\left(\mathrm{T}_{\mathrm{c}}\right)$ yang diperoleh dari blok 1 adalah sebesar 3,24 jam, blok 2 sebesar 1,78 jam dan blok 3 sebesar 1,26 jam.

\subsubsection{Intensitas hujan}

Intensitas hujan dihitung berdasarkan rumus mononobe. Dimana dalam penelitian ini akan dihitung intesitas hujan untuk periode ulang 5 tahun. Intensitas hujan rata-rata yang diperoleh adalah sebesar $102,32 \mathrm{~mm} / \mathrm{jam}$.

\subsubsection{Debit rencana}

Debit limpasan atau debit rencana dalam penelitian ini dihitung dengan menggunakan Metode Rasional. Hasil perhitungan debit total limpasan yang di dapat dengan periode ulang 5 tahun dari ketiga blok sistem drainase di Kota Lhokseumawe adalah sebesar $42,17 \mathrm{~m}^{3} /$ det.

\subsubsection{Kapasitas waduk}

Hasil perhitungan dari penelusuran banjir dan analisis hidrologi dapat diketahui bahwa waduk atau reservoir mampu untuk menampung jumlah debit yang mengalir terus-menerus dari Kota Lhokseumawe pada saat terjadinya hujan dengan jangka waktu maksimum adalah selama 6,74 jam.

\section{Kesimpulan dan Saran}

\subsection{Kesimpulan}

Berdasarkan dari hasil analisis penelusuran banjir dan analisis hidrologi, dapat disimpulkan sebagai berikut:

1. Waduk Lhokseumawe dengan luas sebesar 60 hektar memiliki volume maksimum sebesar $1023440,987 \mathrm{~m}^{3}$, dengan debit inflow maksimum adalah sebesar $25,48 \mathrm{~m}^{3} / \mathrm{det}$, debit outflow maksimum sebesar $4,637 \mathrm{~m}^{3} / \mathrm{det}$ serta jumlah tampungan maksimum yang dimiliki oleh reservoir adalah sebesar $856,49 \mathrm{~m}^{3} /$ det.

2. Dalam melakukan analisis hidrologi untuk mengetahui besarnya debit aliran digunakan periode ulang 5 tahun yang meliputi atas 3 blok sistem drainase di Kota Lhokseumawe dimana blok 1 seluas $1,017 \mathrm{~km}^{2}$, blok 2 seluas $0,624 \mathrm{~km}^{2}$, danblok 3 seluas $0,575 \mathrm{~km}^{2}$ dengan intensitas hujan sebesar 102,32 mm/jam, sehingga diketahui jumlah total debit yang mengalir ke reservoir adalah sebesar $42,17 \mathrm{~m}^{3} /$ det. 
3. Waduk mampu untuk menampung jumlah debit yang mengalir dari Kota Lhokseumawe pada saat kondisi hujan dengan jangka waktu maksimum adalah selama 6,74 jam. Dengan jangka waktu maksimum tersebut dapat diketahui pula bahwa pada saat kondisi hujan secara terus-menerus tanpa adanya proses outflow yang mengakibatkan volume tampungan di reservoir semakin bertambah danpenuh, maka akan memungkinkan terjadinya limpasan balik ke saluran-saluran primer dan sekunder yang nantinya mengakibatkan banjir atau genangan di daerah sekitaran reservoir.

\subsection{Saran}

Berdasarkan dari hasil penelitian dan kesimpulan di atas dapat diberikan saran-saran sebagai berikut:

1. Dalam penelitian ini diasumsikan bahwa semua air yang mengalir dalam keadaan lancar sehingga faktor-faktor penghambat aliran seperti sampah dan sedimentasi tidak diperhitungkan. Selain itu, jumlah curah hujan yang terjadi di reservoir dan air yang tertampung di dalamnya pada saat tidak terjadi hujan juga tidak diperhitungkan.Oleh karena itu diperlukan penelitian lebih lanjut untuk menentukan jumlah debit yang tertampung, agar saat terjadinya pendangkalan pada saluran dan tampungan akibat sedimentasi dapat dilakukan penanggulangan yang berupa pengangkatan sedimentasi secara berkala sehingga kapasitas tampungan tetap terjaga, aman dari peluapan dan efektif sebagai bangunan pengendali banjir.

2. Sebaiknya untuk menjaga keefektifan reservoir sebagai salah satu bangunan pengendali banjir di Kota Lhokseumawe agar terus berdampak positif dan aman dari banjir, penduduk setempat harus selalu menjaga kebersihan sistem drainase dari tumpukan sampah yang mengakibatkan pendangkalan dan penyumbatan pada saluran.

\section{Daftar Kepustakaan}

Chow, V.T., Maidment, David R., Mays, Larry W., 1988, Applied Hydrology, Mcgraw-Hill International Editions.

Chow, V.Te, 1992, Hidrolika Saluran Terbuka, terjemahan Nensi Rosalina, Erlangga, Jakarta.

Kamiana, I Made, 2011, Teknik Perhitungan Debit Rencana Bangunan Air, Graha Ilmu, Yogyakarta.

Loebis, Joesron, 1992, Banjir Rencana untuk Bangunan Air, Yayasan Badan Penerbit Pekerjaan Umum, Jakarta.

Suripin, 2004, Sistem Drainase Perkotaan yang Berkelanjutan, Andi Offset, Yogyakarta.

Suyono, Sosrodarsono., Takeda, Kensaku, 1976, Hidrologi untuk Pengairan, PT. PragnyaParamita, Jakarta.

Triatmodjo, Bambang., 1993, Hidraulika II, Beta Offset, Yogyakarta.

Wesli, 2008, Drainase Perkotaan, Graha Ilmu, Yogyakarta. 